\title{
Design Decision Support for Steel Frame Buildings through Earthquake-Induced Loss Assessment
}

\author{
Seong-Hoon Hwang ${ }^{1}$, Ahmed Elkady ${ }^{2}$, Dimitrios Lignos, A.M.ASCE ${ }^{3}$
}

${ }^{1}$ Graduate Student, McGill University, 817 Sherbrooke West, Room 165, Montreal, QC, H3A 2K6, Canada. E-mail: seong-hoon.hwng@ mail.mcgill.ca

${ }^{2}$ Graduate Student, McGill University, 817 Sherbrooke West, Room 165, Montreal, QC, H3A 2K6, Canada. E-mail: ahmed.elkady@ mail.mcgill.ca

3 Associate Professor, McGill University, 817 Sherbrooke West, Room 278C, Montreal, QC, H3A 2K6, Canada. E-mail: dimitrios.lignos@ @cgill.ca

\begin{abstract}
In recent years, there is an increasing need to quantify earthquake-induced losses throughout the expected life of a building in order to evaluate alternative design options such that we can minimize repairs in the aftermath of an earthquake. This paper discusses an analytical study that quantifies the expected economic losses in a portfolio of archetype steel frame buildings designed with perimeter special moment frames or special concentrically braced frames in urban California in accordance with current seismic provisions in the U.S. The expected economic losses associated with repair are computed based on an established loss estimation framework within the context of Performance-Based Earthquake Engineering. It is shown that repair costs in the aftermath of earthquakes vary significantly depending on the employed lateral load-resisting system, seismic design considerations as well as the analytical model representation of the archetype frame building itself.
\end{abstract}

\section{INTRODUCTION}

Recent earthquakes around the world have demonstrated that seismic code provisions in developed countries are effective in terms of life safety. This is due to the small number of building collapses and the observed seismic performance of recently constructed and retrofitted infrastructure. However, buildings designed with conventional construction practices that do not incorporate response modification devices may exhibit significant economic losses due to damage into their structural and nonstructural content (Kasai et al. 2013). Therefore, it is very important to quantify such losses throughout the expected life of a building in order to evaluate alternative design options and to minimize repair actions in the aftermath of an earthquake. The next generation of performance-based earthquake engineering evaluation procedures (FEMA 2012a, b) has formalized a computational framework that utilizes several metrics for assessing the seismic performance of a frame building including economic losses. This framework was established within the Pacific Earthquake Engineering Research Center (PEER) center (Cornell and Krawinkler 2000). This can be particularly valuable for stakeholders and building owners in order to take informed decisions for the utilization of effective designs and/or seismic retrofits that minimize building repairs in the aftermath of an earthquake. This 
framework integrates site-specific seismic hazard, state-of-the-art nonlinear component models that simulate cyclic deterioration in strength and stiffness of various structural components, fragility curves of structural and nonstructural components that express the probability of being or exceeding a specific damage level, and the resulting repair costs. Prior studies are available for reinforced concrete (RC) buildings and wood structures (Liel and Deierlein 2008, Pei and van de Lindt 2009, Porter et al. 2006, Ramirez et al. 2012, Shoraka et al. 2013). Most of these studies have mainly utilized a building-specific loss estimation methodology without considering the effect of residual deformations along the height of a building on earthquake-induced losses. However, this assumption may be misleading in terms of loss computations and subsequently building repair actions (Ramirez and Miranda 2012).

This paper discusses an analytical study that quantifies the expected earthquake-induced losses in archetype steel frame buildings designed with perimeter special moment frames (SMFs) or perimeter special concentrically braced frames (SCBFs) at various ground motion intensities. These buildings are designed in urban California in accordance with today's seismic design provisions in North America. The emphasis of the present paper is on the effects of the employed lateral loadresisting system as well as the analytical model representation of the archetype frame building on the earthquake-induced losses. Furthermore, the impact of the variation of key seismic design parameters on the computed losses is quantified.

\section{OVERVIEW OF LOSS ESTIMATION METHODOLOGY}

The main aspects of the employed loss estimation methodology are summarized herein. By assuming mutually exclusive and collectively exhaustive events of building collapse and no collapse, the expected loss in a frame building for a given seismic intensity $I M=i m$ (i.e., $E\left[L_{T} \mid I M\right]$ ) can be computed as follows,

$$
E\left[L_{T} \mid I M\right]=E\left[L_{T} \mid I M, N C\right]\left(1-P_{C \mid I M}\right)+E\left[L_{T} \mid C\right] P_{C \mid I M}
$$

in which, $E\left[L_{T} \mid I M, N C\right]$ is the mean value of the loss conditioning on no collapse for a given $I M=i m ; E\left[L_{T} \mid C\right]$ is the mean value of the loss given collapse; and $P_{C \mid I M}$ is the collapse probability given $I M=i m$. By adopting the methodology proposed by Ramirez and Miranda (2012), $E\left[L_{T} \mid I M, N C\right]$ is further disaggregated into losses due to structural and nonstructural building content repairs and losses due to building demolition, both conditioned on no collapse. Therefore, Eq.(1) can be rewritten as follows,

$$
\begin{aligned}
E\left[L_{T} \mid I M\right]= & E\left[L_{T} \mid R, I M, N C\right] P_{R \mid I M, N C}\left(1-P_{C \mid I M}\right) \\
& +E\left[L_{T} \mid D, I M, N C\right] P_{D \mid I M, N C}\left(1-P_{C \mid I M}\right)+E\left[L_{T} \mid C\right] P_{C \mid I M}
\end{aligned}
$$

in which, $E\left[L_{T} \mid R, I M, N C\right]$ is the mean value of building losses conditioned on no collapse, given that a building is repaired with seismic intensity $I M=i m$; $E\left[L_{T} \mid D, I M, N C\right]$ is the mean value of losses in the building conditioned on no collapse, given that the building is demolished with seismic intensity $I M=i m ; P_{R \mid I M, N C}$ and $P_{D \mid I M, N C}$ are the probabilities that the building is being considered to be repaired and 
be demolished, respectively, conditioned on no collapse given a seismic intensity $I M=i m$; therefore, Eq. (2) becomes,

$$
\begin{aligned}
E\left[L_{T} \mid I M\right]= & E\left[L_{T} \mid R, I M, N C\right]\left(1-P_{D \mid I M, N C}\right)\left(1-P_{C \mid I M}\right) \\
& +E\left[L_{T} \mid D, I M, N C\right] P_{D \mid I M, N C}\left(1-P_{C \mid I M}\right)+E\left[L_{T} \mid C\right] P_{C \mid I M}
\end{aligned}
$$

In this paper, $E\left[L_{T} \mid R, I M, N C\right]$ is estimated using Eq. (5),

$$
E\left[L_{T} \mid R, I M, N C\right]=\sum_{i=1}^{m} \sum_{j=1}^{n} \int_{0}^{\infty} E\left[L_{i} \mid D S_{j}\right] P_{D S_{j} \mid E D P} f_{E D P \mid I M} \mathrm{~d} E D P
$$

in which, $E\left[L_{i} \mid D S_{j}\right]$ is the mean repair cost for the $i$ th component, given the $j$ th damage state, $d s$ of the component; $P_{D S j \mid E D P}$ is the probability of a component being in the $i$ th damage state given an engineering demand parameter $(E D P) E D P=e d p$; and $f_{E D P \mid I M}$ is the probability density function of the $E D P$ of interest given $I M=i m$. In order to estimate the probability that a building will be demolished given that it did not collapse when subjected to an earthquake with seismic intensity $I M=i m$, the following relationship can be employed,

$$
P_{D \mid I M}=\int_{0}^{\infty} P_{D \mid R S D R} f_{D \mid R S D R} \mathrm{~d} R S D R
$$

in which, $f(R S D R \mid I M)$ is the probability density function of the maximum residual drift ratio along the height of the building, given intensity measure $I M=i m$; $P(D \mid R S D R)$ is the probability of having to demolish the building conditioned on the maximum residual story drift ratio, $R S D R$, along the height of the building, which is assumed to be a lognormal distribution, defined by a mean, $\mu_{\ln }=0.015$ and a logarithmic standard deviation, $\sigma_{\mathrm{ln}}=0.3$ as suggested by Ramirez and Miranda (2012). These parameters are based on on engineering judgment. It is desired to determine the relationship between the EDP of interest associated with a measure of seismic demand in the frame building (e.g., story drift ratio, residual drift ratio, peak floor absolute acceleration, etc.) and seismic intensity measure $I M=i m$ during the earthquake for the integration process over the entire range of EDP. In this paper, the mean $\mu_{E D P \mid I M}$ and the standard deviation $\sigma_{\ln E D P \mid I M}$ of the parameters given the $I M=i m$ are described by a power-law model form, which is fitted to the discrete data points obtained from nonlinear response history analyses (i.e., $\mu_{E D P \mid I M}=a(I M)^{b}, \sigma_{\ln E D P \mid I M}=$ $\left.c(I M)^{d}\right)$.

\section{DESCRIPTION OF ARCHETYPE STEEL FRAME BUILDINGS}

Three steel buildings with perimeter steel SMFs and steel SCBFs are considered as part of the present study. In particular, two 12-story steel frame buildings with perimeter SMFs designed with different strong column/weak beam (SCWB) ratios are considered. This is done in order to investigate the effect of SCWB ratio on earthquake-induced losses of steel frame buildings with SMFs. The third building is a 12-story steel frame building with perimeter SCBFs. All steel buildings are assumed to be office buildings (i.e., occupancy category II) located in the Bulk mail center $\left(33.996^{\circ} \mathrm{N}, 118.162^{\circ} \mathrm{W}\right)$ in downtown of Los Angeles. This 
location represents a high seismicity region in urban California (Goulet et al. 2007). It is assumed that the design site is class $D$ and an upper bound of Seismic Design Category $D$ (i.e., SDC $D_{\max }$ ). Figure 1 illustrates the design spectrum and hazard curves for the three steel frame buildings under consideration.

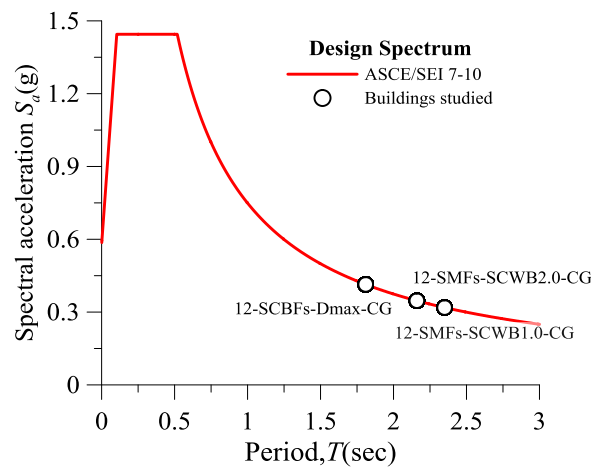

(a)

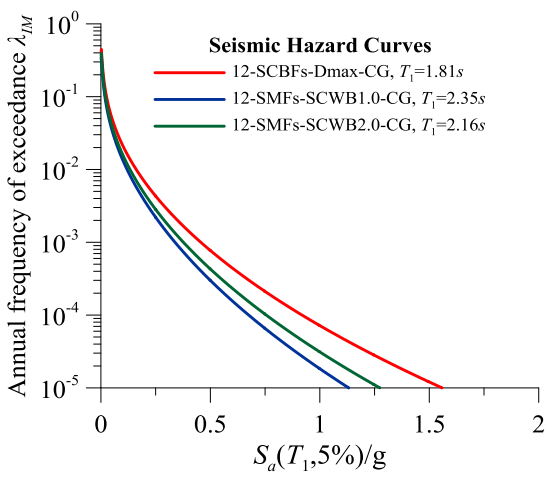

(b)

Figure 1. Design spectrum and seismic hazard curves at the site of interest.

Figure 2 illustrates the floor plan and elevation view of the buildings considered as part of this paper. All the buildings are designed in accordance with current seismic provisions in North America (AISC 2010a, b, ASCE 2010). The steel frame buildings with perimeter SMFs utilize fully-restrained reduced beam section (RBS) moment connections designed in accordance with ANSI/AISC 358-10 (AISC 2010b). The steel frame buildings with perimeter SCBFs are designed with round steel hollow structural sections (HSSs) as discussed in NIST (2010). The gusset plates at the ends of the braces were designed according to balanced design criteria proposed by and Roeder et al. (2011). More details regarding the building designs can be found in (Elkady and Lignos 2013, 2014, 2015) and NIST (2010). An important detail that should be mentioned is that the interior gravity framing system (e.g., the floor system and gravity columns) of the three steel frame buildings was explicitly designed based on ANSI/AISC-360-10 (AISC 2010c). Its effect on the earthquakeinduced losses of the aforementioned buildings is quantified as discussed later on.

\section{Fragility and cost distribution functions}

In order to realistically estimate the earthquake-induced losses in steel frame buildings under consideration it is necessary to first develop their architectural layout. The rectangular floor area of the steel frame buildings with perimeter SMFs and SCBFs is assumed to be $1300.65 \mathrm{~m}^{2}\left(14,000 \mathrm{ft}^{2}\right)$ and $2006.71 \mathrm{~m}^{2}\left(21,600 \mathrm{ft}^{2}\right)$, respectively, (see Figures $2 \mathrm{a}$ and $\mathrm{b}$ ). The replacement costs for the three buildings are tabulated in Table 1. The fragility distribution functions for damageable components such as structural, drift-sensitive, and acceleration-sensitive nonstructural components are essential for the realistic estimation of earthquake-induced losses due to their repair. These component-based fragility functions are intended to estimate the probability of reaching or exceeding different damage states as a function of the $E D P$ s of interest. Repair costs for considered damageable components were developed using the RS Means Cost Estimating Manuals (RS Means 2013). Due to brevity, more details regarding repair costs for damageable components together with 
their fragility distribution functions used in this paper can be found in previous work by the authors Hwang et al. (2015).

Table 1. Replacement cost estimates for steel frame buildings studied.

\begin{tabular}{lcccc}
\hline Building identifier & Floor area & Total area $\left(\mathrm{m}^{2}\right)$ & $\begin{array}{c}\text { Replacement } \\
\text { cost }(\$)\end{array}$ & $\begin{array}{c}\mathrm{Cost} / \mathrm{m}^{2} \\
\left(\$ / \mathrm{m}^{2}\right)\end{array}$ \\
\hline 12-SMF-SCWB1.0 & $42.5 \mathrm{~m} \times 30.5 \mathrm{~m}$ & 15607.77 & $21,000,000$ & 1345.49 \\
12-SMF-SCWB2.0 & $42.5 \mathrm{~m} \times 30.5 \mathrm{~m}$ & 15607.77 & $21,756,000$ & 1393.93 \\
12-SCBF-Dmax & $36.4 \mathrm{~m} \times 54.6 \mathrm{~m}$ & 24080.56 & $45,360,000$ & 1883.69 \\
\hline
\end{tabular}

\section{BUILDING MODELS AND NONLINEAR RESPONSE HISTORY ANALYSES THROUGH COLLAPSE}

Nonlinear analytical model representations of the considered steel frame buildings are developed in the Open System for Earthquake Engineering Simulation (OpenSees) platform (Mckenna 1997). The seismic load resisting system of each building located in the east-west (E-W) loading direction (see Figure 2) was modeled with 2-Dimensional (2-D) frames, denoted by red bold line in Figures 2(a) and 2(b).

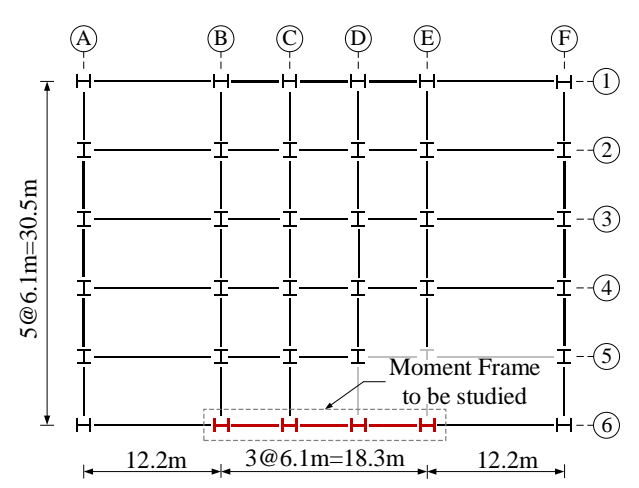

(a)

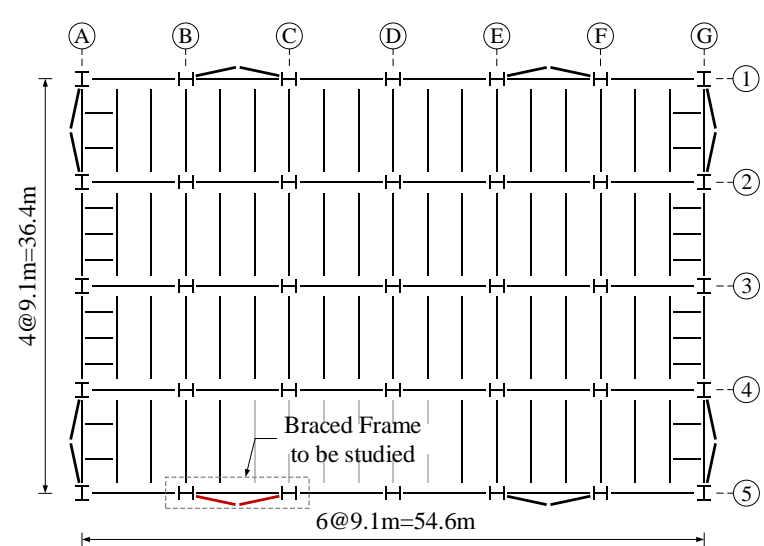

(b)
Note:

Gravity Loads

1. Roof Loading

Moment Frame

Dead $=4.31 \mathrm{kPa}$

Live $=0.96 \mathrm{kPa}$

2. Floor Loading

Moment Frames

Dead $=4.31 \mathrm{kPa}$

Live $=2.39 \mathrm{kPa}$

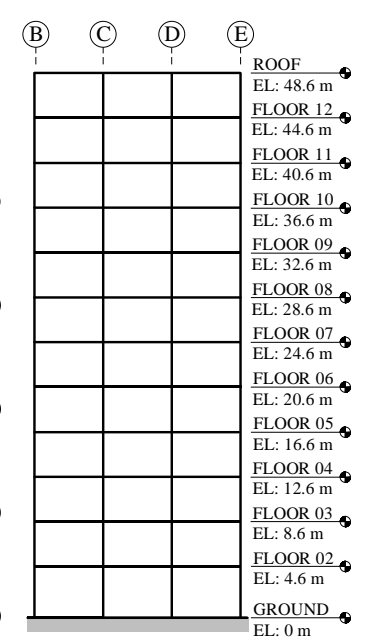

(c)

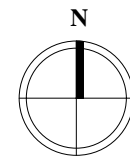

Braced Frames

Dead $=3.21 \mathrm{kPa}$

Live $=0.96 \mathrm{kPa}$

Braced Frames

Dead $=4.07 \mathrm{kPa}$

Live $=2.39 \mathrm{kPa}$
Seismic Design Parameters

Los Angeles, California

Occupancy Category II

(office)

Importance Factor $=1.0$ Seismic Design Category $D$ $S_{D S}=1.4 \mathrm{~g}, S_{D 1}=0.7 \mathrm{~g}$

$F_{a}=1.0, F_{v}=1.5$

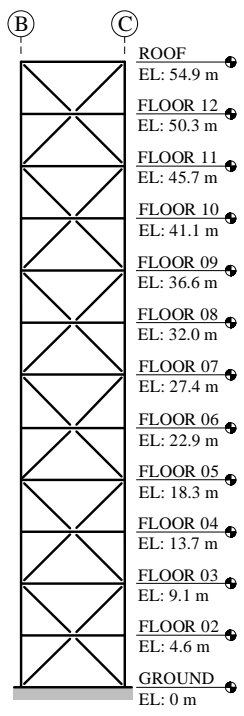

(d)

Figure 2. Steel office buildings with perimeter SMFs and SCBFs.

The steel beams and columns in SMFs are modeled as elastic elements with concentrated plastic hinges at their ends that simulate the cyclic deterioration in strength and stiffness of the respective component as discussed in Ibarra et al. (2005) and Lignos and Krawinkler (2011). Modeling recommendations by Elkady and Lignos (2014) are employed to simulate the effect of composite action on the 
hysteretic response of fully-restrained RBS moment connections. In order to quantify the effect of the gravity framing system on the earthquake-induced losses, the modeling recommendations proposed by Elkady and Lignos (2015) are utilized.

In the case of SCBFs, the braces are modeled using fiber-based elements that are able to trace flexural buckling and fracture initiation due to low-cycle fatigue. These are considered based on the modeling recommendations by Karamanci and Lignos (2014). Moreover, an additional nonlinear rotational spring is placed at the end of the brace to explicitly simulate the flexibility and potential flexural yielding of the gusset plates due to out-of-plane brace bending as discussed in Hsiao et al. (2013). Cyclic deterioration in flexural strength and stiffness of SCBF beams and columns including the effect of gravity framing system are simulated based on the approach discussed in Karamanci and Lignos (2014). In order to illustrate the impact of the gravity framing on the earthquake-induced losses in the case of the steel frame building with SCBFs two different analytical models are developed; the first one includes only the bare steel structural components (i.e., bare SCBFs model, hereafter referred to as $B$-model); and the second one is a model that includes the effect of the composite slab and the interior gravity framing system on the lateral strength and flexural stiffness of the steel frame building (i.e., hereafter referred to as $C G$-model).

The analytical model representations of the considered steel frame buildings are subjected to the set of 44 Far-Field ground motions obtained from FEMA P695 (FEMA 2009). This set represents large magnitude earthquakes ranging from 6.5 to 7.6, recorded on rock or stiff soil sites (i.e., site classes $C$ or $D$ ). These motions represent well the seismic hazard of the design location. Incremental dynamic analysis (IDA) (Vamvatsikos and Cornell 2002) is performed in order to trace the dynamic collapse due to sidesway instability for each analytical model. The EDPs of interest [i.e., peak story drift ratios (SDRs), peak absolute floor accelerations (PFAs), residual story drift ratios (RSDRs)] are obtained for each ground motion over the entire range of structural response from elastic behavior through collapse. Figures 3(a) and 3(b) illustrate the peak SDRs and PFAs with respect to $I M$ [i.e., the 5\% damped spectral acceleration at the first mode of the building $S_{a}\left(T_{1}, 5 \%\right)$, respectively, obtained from the $C G$-model of the 12-story steel frame building with SCBFs. The counted median, 16th and 84th percentiles value determined based on the suite of 44 ground motions are superimposed in the same figures. The collapse fragility curve is computed for the $C G$-model that describes the probability of collapse $P_{C \mid I M}$ as a function of spectral acceleration, $S_{\mathrm{a}}\left(T_{1}, 5 \%\right)$ as illustrated in Figure 3(c).

\section{EXPECTED LOSSES CONDITIONED ON SEISMIC INTENSITY}

The expected losses are computed as function of the seismic intensity, $S_{a}\left(T_{1}\right.$, $5 \%$ ), as illustrated in Figures 4(a) and 4(b) for the $B$ - and $C G$-models representations, respectively, of the 12-story steel frame building with SCBFs. Note that these curves are also known as the loss vulnerability curves (Ramirez et al. 2012). The expected losses due to repair of damageable components conditioned on a seismic intensity are further disaggregated into losses due to repair of structural, drift-sensitive and acceleration-sensitive nonstructural components conditioned on no collapse. In these figures the expected losses in the frame building are normalized with respect to the corresponding building replacement cost (see Table 1). Moreover, the additional 
horizontal axes represent the normalized seismic intensity by its design-level earthquake (DLE) as specified in ASCE/SEI 7-10 (ASCE 2010).

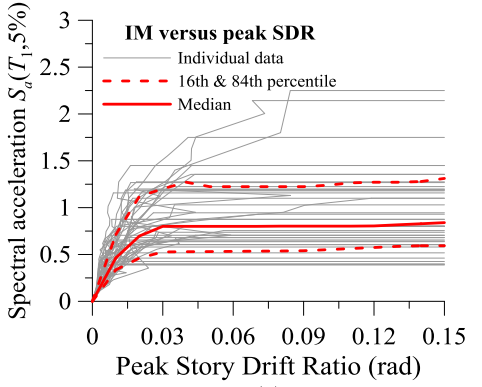

(a)

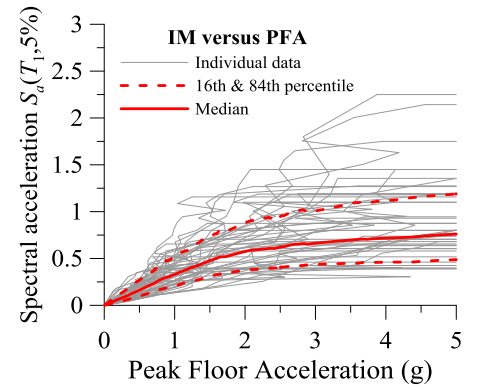

(b)

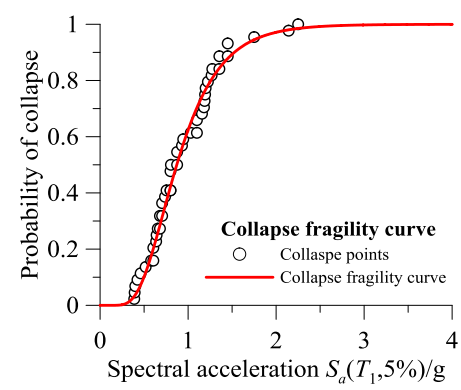

(c)

Figure 3. Critical EDPs and collapse fragility curves for steel frame buildings with perimeter SCBFs.

For the $B$-model representation of the 12-story steel frame building with SCBFs under a service-level earthquake [i.e., SLE: $S_{a}\left(T_{1}, 5 \%\right)=0.13 \mathrm{~g}$ ], the expected losses are governed by nonstructural component damage [see Figure 4 (c)]. However, under the DLE intensity [i.e., $S_{a}\left(T_{1}, 5 \%\right)=0.40 \mathrm{~g}$ ] the expected losses due to structural repairs is considerable. These losses are approximately equal to $20 \%$ of the replacement cost of the 12-story steel frame building with SCBFs [see Figure 4(c)]. This is mostly attributed to flexural buckling of the steel round HSS braces at story drift levels in the range of $0.5 \%$ (Lignos and Karamanci 2013). From the same figures, another notable observation is that at higher seismic intensities associated with a maximum considered earthquake (MCE) losses are governed by building demolition due to large residual deformations along its height as well as losses due to structural collapse. This observation agrees with earlier findings on code-compliant RC frame buildings (Ramirez and Miranda 2012). Note that when the bare frame is only considered as part of the analytical model representation of the 12-story steel frame building with SCBFs losses due to demolition are approximately equal to $40 \%$ of the building replacement cost as shown in Figure 4(c).

Figure 4(b) illustrates the loss vulnerability curves for the $C G$-model of the 12-story steel frame building with SCBFs. From this figure, the findings associated with (a) the magnitude of earthquake losses and (b) the primary contributors to the total losses for low to moderate seismic intensities (i.e., SLE, DLE), which correspond to more frequently occurring seismic events, are practically the same with the ones obtained based on the $B$-model representation. It is noteworthy to mention that for the $C G$-model of the 12-story steel frame building with SCBFs the losses due to demolition at the MCE intensity become much smaller than those computed based on the $B$-model of the same building as shown in Figure 4(d). This is due to the fact that in reality there is much less drift concentration in the bottom stories of steel frame buildings with SCBFs when the interior gravity framing is included into the analytical model (Ji et al. 2009). However, losses due to collapse are practically the same regardless of the employed analytical model representation of the considered building. This is attributed to the fact that a uniform demand-to-capacity ratio along the height of steel buildings with SCBFs is practically unachievable; therefore, local 
story mechanisms associated with concentration of plastic deformations cannot be easily avoided. These mechanisms trigger structural collapse.

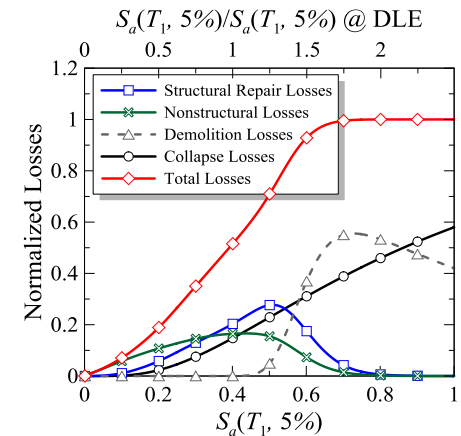

(a) 12-story steel building with SCBFs (B-model)

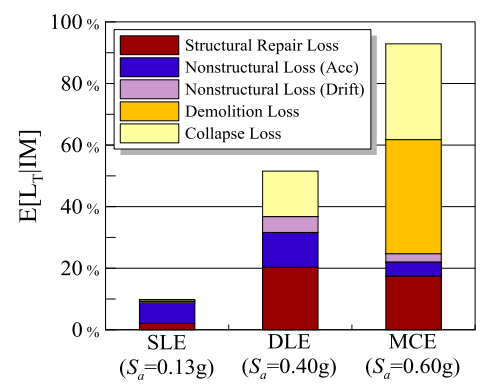

(c) 12-story steel building with SCBFs (B-model)

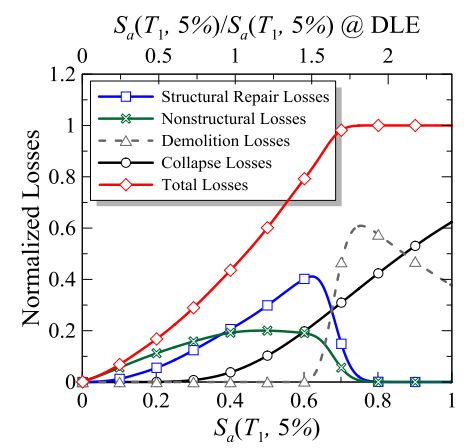

(b) 12-story steel building with SCBFs (CG-model)

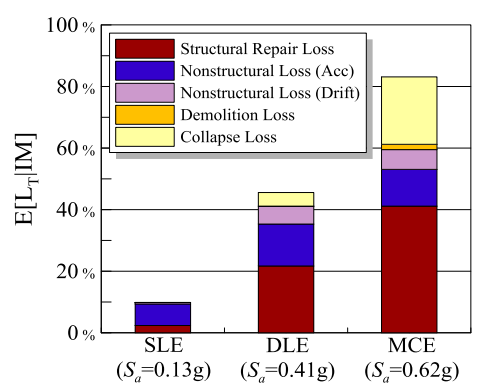

(d) 12-story steel building with SCBFs (CG-model)

Figure 4. Normalized expected losses for steel frame buildings with perimeter SCBFs conditioning on seismic intensity.

In order to examine how earthquake-induced losses in steel frame buildings with perimeter SMFs are affected by the employed Strong-Column-Weak-Beam (SCWB) ratio the two $C G$-models of the steel frame buildings with perimeter SMFs designed with SCWB > 1.0 (i.e., current seismic design provisions) and $>2.0$ are considered. From the results of normalized expected losses illustrated in Figure 5, at low to moderate seismic intensities (i.e., SLE, DLE), same observations with steel frame buildings with SCBFs hold true. Note that the effect of SCWB ratio on the structural repair losses is not significant at these intensities. This is due to the fact that steel columns would normally remain elastic at moderate seismic intensities excluding the base location of first story columns as part of steel SMFs. However, it is worth mentioning that when a higher SCWB ratio is considered as part of the design process in steel SMFs a considerable decrease in losses due to demolition and collapse can be achieved. The contribution of structural repair losses to total economic losses typically increases with an increase of the SCWB ratio. From Figure 5 , an increase of the SCWB ratio results to a decrease of the collapse potential and residual story drift ratios along the height of steel SMFs. In addition, the lateral deformation over the height of steel SMFs distributes more evenly with an increase in SCWB ratio; thereby more damage is observed to structural and nonstructural components (Elkady and Lignos 2014, Ramirez et al. 2012). For example, the demolition losses of the 12-story steel frame building with SCWB $>2.0$ are decreased by $60.65 \%$ relative to that of the building with SCWB $>1.0$. 


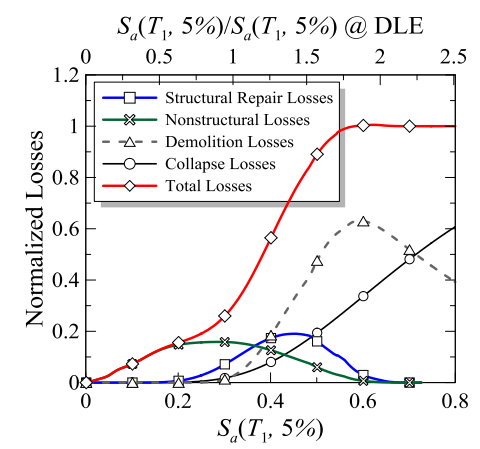

(a) 12-story steel building with SMFs $(\mathrm{SCWB}>1.0)$

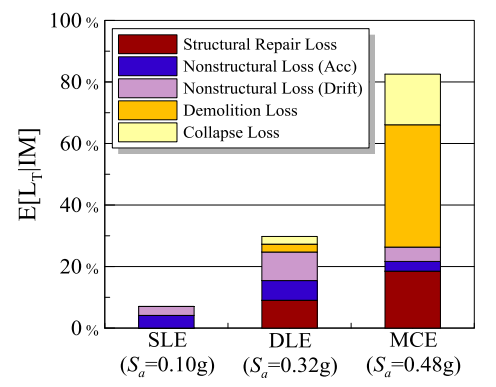

(b) 12-story steel building with SMFs $(\mathrm{SCWB}>1.0)$

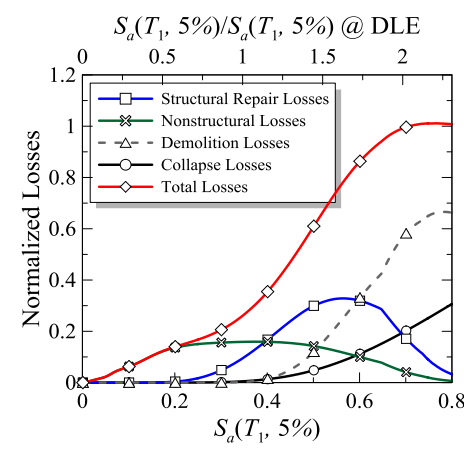

(c) 12-story steel building with SMFs $(\mathrm{SCWB}>2.0)$

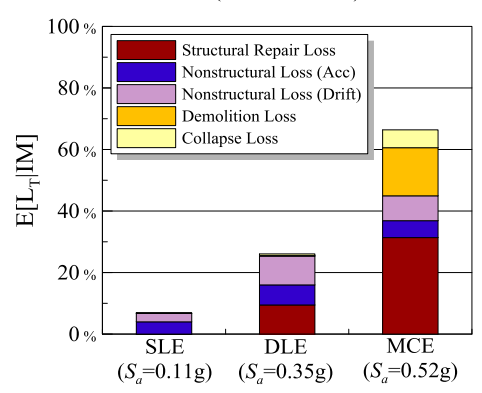

(d) 12-story steel building with SMFs
(SCWB $>2.0)$

Figure 5. Normalized loss vulnerability functions for steel frame buildings with perimeter SMFs conditioned on seismic intensity.

\section{EXPECTED ANNUAL LOSSES}

This section discusses the utilization of the normalized expected annual losses (EALs) to evaluate the earthquake-induced losses of the three steel frame buildings studied. The EAL used in this paper is computed as follows,

$$
E\left[L_{T}\right]=\int_{0}^{\infty} E\left[L_{T} \mid I M\right] \mathrm{d} \lambda_{I M}=\int_{0}^{\infty} E\left[L_{T} \mid I M\right]\left|\frac{\mathrm{d} \lambda_{I M}}{\mathrm{~d} I M}\right| \mathrm{d} I M
$$

in which, $\lambda_{I M}$ is the mean annual frequency of the ground motion intensity at the design site (see Figure 1(b)). Figure 6 illustrates the normalized EAL for the 12-story steel frame buildings with perimeter SCBFs and SMFs. Based on this figure, the EAL values vary between 0.47 to $0.80 \%$ of the replacement cost for the steel frame buildings. From Figure 6, the drift-sensitive nonstructural components of steel buildings with perimeter SMFs contribute more to the total EALs than the equivalent $E A L$ values for steel frame buildings with SCBFs. This is to be expected given that steel frame buildings with SMFs are normally more flexible than those with SCBFs. However, due to their increased lateral stiffness steel buildings with perimeter SCBFs tend to have approximately $70 \%$ higher EALs than those with SMFs mostly due to acceleration-sensitive nonstructural component repairs. An interesting observation is that the effect of SCWB ratio in steel buildings that utilize SMFs on $E A L$ is practically negligible. This is due to the fact that EALs are calculated considering all possible levels of seismic hazard at the site. Therefore, the contribution of seismic intensities not associated with structural collapse is more pronounced. The SCWB 
ratio is a parameter that mostly affects the formation of bottom story collapse mechanisms in SMFs.

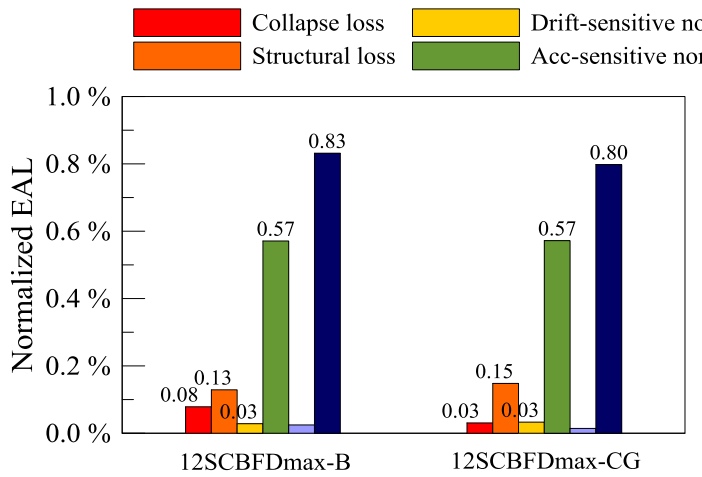

(a) 12-story steel buildings with perimeter SCBFs

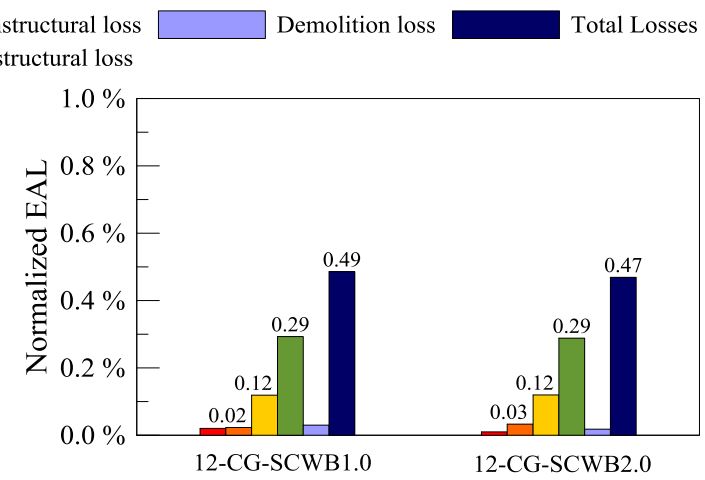

(b) 12-story steel buildings with perimeter SMFs

Figure 6. Normalized expected annual losses for steel frame buildings with perimeter SMFs and SCBFs.

\section{CONCLUSIONS}

This paper assesses the earthquake-induced losses in steel frame buildings. Two lateral load-resisting systems are examined (i.e., special moment frames and special concentrically braced frames). The main findings are summarized as follows:

- At low seismic intensities, damage to the nonstructural content of a steel frame building is the primary contributor to building economic losses regardless of the employed lateral load-resisting system as well as the seismic design criteria.

- At seismic intensities associated with design level earthquakes, steel frame buildings with SCBFs experience considerable structural repair losses due to steel brace flexural buckling at fairly small story drift ratios. This is also confirmed when $E A L$ is utilized as a loss-metric.

- Earthquake-induced losses in steel frame buildings at seismic intensities associated with a MCE may be significantly overestimated when the interior gravity framing and the composite action are neglected in the analytical model representation of the building under consideration.

- Losses due to demolition in steel frame buildings with SMFs designed with a SCWB > 2.0 are reduced by a factor of three compared to those of the same SMFs designed with a SCWB $>1.0$.

- The effect of analytical model representation and SCWB ratios is not significant on EALs because this loss-metric is affected by frequently occurring seismic events (i.e., the event with low seismic intensity). However, the analytical model representation as well as the employed SCWB ratio significantly affects the computation of earthquake-induced losses associated with extreme seismic events (e.g., MCE seismic intensities).

\section{REFERENCES}

AISC (2010a). "Seismic provisions for structural steel buildings." ANSI/AISC 341-10, American Institute of Steel Construction (AISC), Chicago, IL. 
AISC (2010b). "Prequalified connections for special and intermediate steel moment frames for seismic applications." ANSI/AISC 358-10, American Institute of Steel Construction (AISC), Chicago, IL.

AISC (2010c). "Specification for structural steel buildings." ANSI/AISC 360-10, American Institute of Steel Construction (AISC), Chicago, IL.

ASCE (2010). "Minimum design loads for buildings and other structures." ASCE/SEI 7-10, American Society of Civil Engineers (ASCE), Reston, VA.

Cornell, C. A., and Krawinkler, H. (2000). "Progress and challenges in seismic performance assessment." PEER Center News, 3(2), 1-4.

Elkady, A., and Lignos, D. G. "Effect of composite action on the dynamic stability of special steel moment resisting frames designed in seismic regions." Proc., Proceedings of ASCE Structures Congress 2013, American Society of Civil Engineers, 2151-2160.

Elkady, A., and Lignos, D. G. (2014). "Modeling of the composite action in fully restrained beam-to-column connections: implications in the seismic design and collapse capacity of steel special moment frames." Earthquake Engineering and Structural Dynamics, 43(13), 1935-1954.

Elkady, A., and Lignos, D. G. (2015). "Effect of gravity framing on the overstrength and collapse capacity of steel frame buildings with perimeter special moment frames." Earthquake Engineering \& Structural Dynamics, 44(8), 1289-1307.

FEMA (2009). "Quantification of building seismic performance factors." Federal Emergency Management Agency (FEMA), Washington, DC.

FEMA (2012a). "Seismic performance assessment of buildings, Volume 1Methodology." prepared by the Applied Technology Council for the Federal Emergency Management Agency, Washington, DC.

FEMA (2012b). "Seismic performance assessment of buildings, Volume 2Implementation Guide." prepared by the Applied Technology Council for the Federal Emergency Management Agency, Washington, DC.

Goulet, C. A., Haselton, C. B., Mitrani-Reiser, J., Beck, J. L., Deierlein, G. G., Porter, K. A., and Stewart, J. P. (2007). "Evaluation of the seismic performance of a code-conforming reinforced-concrete frame building-from seismic hazard to collapse safety and economic losses." Earthquake Engineering and Structural Dynamics, 36(13), 1973-1997.

Hsiao, P.-C., Lehman, D. E., and Roeder, C. W. (2013). "A model to simulate special concentrically braced frames beyond brace fracture." Earthquake Engineering and Structural Dynamics, 42(2), 183-200.

Hwang, S.-H., Elkady, A., Al.Bardaweel, S., and Lignos, D. G. "Earhtuqake loss assessment of steel frame buildings desinged in highly seismic regions." Proc., Proceedings of 5th ECCOMAS Thematic Conference on Computational Methods in Structural Dynamics and Earthquake Engineering.

Ibarra, L. F., Medina, R. A., and Krawinkler, H. (2005). "Hysteretic models that incorporate strength and stiffness deterioration." Earthquake Engineering and Structural Dynamics, 34(12), 1489-1511.

Ji, X., Kato, M., Wang, T., Hitaka, T., and Nakashima, M. (2009). "Effect of gravity columns on mitigation of drift concentration for braced frames." Journal of Constructional Steel Research, 65(12), 2148-2156. 
Karamanci, E., and Lignos, D. G. (2014). "Computational approach for collapse assessment of concentrically braced frames in seismic regions." Journal of Structural Engineering, 140(8), A4014019.

Kasai, K., Mita, A., Kitamura, H., Matsuda, K., Morgan, T. A., and Taylor, A. W. (2013). "Performance of Seismic Protection Technologies during the 2011 Tohoku-Oki Earthquake." Earthquake Spectra, 29(S1), S265-S293.

Liel, A. B., and Deierlein, G. G. (2008). "Assessing the collapse risk of California's existing reinforced concrete frame structures: metrics for seismic safety decisions." John A. Blume Earthquake Engineering Center, Stanford University, Stanford, CA.

Lignos, D. G., and Krawinkler, H. (2011). "Deterioration modeling of steel components in support of collapse prediction of steel moment frames under earthquake loading." Journal of Structural Engineering, 137(11), 1291-1302.

Lignos, D. G., and Karamanci, E. (2013). "Drift-based and dual-parameter fragility curves for concentrically braced frames in seismic regions." Journal of Constructional Steel Research, 90(0), 209-220.

Mckenna, F. T. (1997). "Object-oriented finite element programming: frameworks for analysis, algorithms and parallel computing." Ph.D. Thesis, University of California, Berkeley, Berkeley, CA.

NIST (2010). "Evaluation of the FEMA P-695 methodology for quantification of building seismic performance factors." NEHRP Consultants Joint Venture, Gaithersburg, MD.

Pei, S., and van de Lindt, J. W. (2009). "Methodology for earthquake-induced loss estimation: an application to woodframe buildings." Structural Safety, 31(1), 31-42.

Porter, K. A., Scawthorn, C. R., and Beck, J. L. (2006). "Cost-effectiveness of stronger woodframe buildings." Earthquake Spectra, 22(1), 239-266.

Ramirez, C. M., Liel, A. B., Mitrani-Reiser, J., Haselton, C. B., Spear, A. D., Steiner, J., Deierlein, G. G., and Miranda, E. (2012). "Expected earthquake damage and repair costs in reinforced concrete frame buildings." Earthquake Engineering and Structural Dynamics, 41(11), 1455-1475.

Ramirez, C. M., and Miranda, E. (2012). "Significance of residual drifts in building earthquake loss estimation." Earthquake Engineering and Structural Dynamics, 41(11), 1477-1493.

Roeder, C. W., Lumpkin, E. J., and Lehman, D. E. (2011). "A balanced design procedure for special concentrically braced frame connections." Journal of Constructional Steel Research, 67(11), 1760-1772.

RS Means (2013). "RS Means Square Foot Costs." RS Means Corporation, Kingston, MA. USA.

Shoraka, M. B., Yang, T. Y., and Elwood, K. J. (2013). "Seismic loss estimation of non-ductile reinforced concrete buildings." Earthquake Engineering \& Structural Dynamics, 42(2), 297-310.

Vamvatsikos, D., and Cornell, C. A. (2002). "Incremental dynamic analysis." Earthquake Engineering and Structural Dynamics, 31(3), 491-514. 